\title{
Ensinando Conceitos sobre a Pandemia com Símbolos Tangíveis ${ }^{1}$ Teaching Pandemic Concepts With Tangible Symbols
}

\author{
Flavia Daniela dos Santos MOREIRA²
}

\begin{abstract}
RESUMO: Crianças com deficiência múltipla sensorial visual enfrentam desafios diários para comunicar seus interesses e necessidades e para compreender adequadamente conceitos. Um dos grandes obstáculos para iniciar uma intervençáo eficaz com essas crianças consiste em identificar suas preferências e fornecer estratégias de ensino e oportunidades de aprendizagem específicas que valorizem os seus pontos fortes. Nesse sentido, o objetivo deste estudo foi apresentar cinco cartóes de símbolos tangíveis como recurso para ensinar conceitos sobre a pandemia da COVID-19 para crianças que apresentam deficiência múltipla sensorial visual. Pensando nisso, este ensaio teórico coloca em evidência a importância dos símbolos tangíveis como valiosos recursos da comunicação alternativa tátil, capazes de favorecer a comunicação, a antecipação de atividades, a compreensão de conceitos, e como opçôes de escolhas a serem feitas por estas crianças. Destaca-se a importância das interaçóes táteis exploratórias por meio da modalidade háptica e do distanciamento entre o eu, os outros, os objetos e as representações. Por tratar-se de um assunto pouco explorado no cenário nacional, considera-se relevante apresentá-lo para que outros professores e pesquisadores o conheçam e o utilizem com seus alunos.
\end{abstract}

PALAVRAS-CHAVE: Educação Especial. Símbolos tangíveis. Deficiência múltipla sensorial visual.

\begin{abstract}
Children with multi-sensory impairment face daily challenges to communicate their interests and needs and properly understand concepts. One of the major obstacles to start an effective intervention with these children is to identify their preferences and provide specific teaching strategies and learning opportunities that value their strengths. In this sense, the objective of this study was to present five cards of tangible symbols as a resource to teach concepts about the COVID-19 pandemic to children who have multi-sensory impairment. With this in mind, this theoretical essay highlights the importance of tangible symbols as valuable resources for alternative tactile communication, capable of favoring communication, anticipating activities, understanding concepts, and as options for choices to be made by these children. It highlights the importance of exploratory tactile interactions through haptic modality and distance between the self, others, objects and representations. As it is a subject little explored in the national scenario, it is considered relevant to present it so that other professors and researchers can get to know it and use it with their students.
\end{abstract}

KEYWORDS: Special Education. Tangible Symbols. Multiple Disability and Visual Impairment.

\section{INTRODUÇÃo}

A pandemia da doença coronavírus (COVID-193) afetou seriamente a vida de toda a população mundial. No entanto, certamente, seu impacto foi mais exacerbado entre as crianças com deficiência, sobretudo aquelas que enfrentam dificuldades para se comunicar de modo funcional. Para essas crianças, estabelecer trocas comunicativas eficazes é, com frequência, um grande desafio.

Essa dificuldade torna-se ainda mais acentuada quando a deficiência envolve comprometimentos sensoriais. Nesse grupo, destacam-se as crianças com deficiência múltipla sensorial visual, as quais podem apresentar cegueira ou baixa visão associada à deficiência intelec-

\footnotetext{
${ }^{1}$ https://doi.org/10.1590/1980-54702021v27e0013

${ }^{2}$ Professora do Instituto Benjamin Constant (IBC). Doutora em Educação pela Universidade do Estado do Rio de Janeiro (UERJ). Pesquisadora de Pós-Doutorado (UERJ). Coordenadora do Grupo de Pesquisa Laboratório de Comunicação Alternativa Tátil (LABCÁTIL-IBC). E-mail: labcatil@ibc.org.br. ORCID: https://orcid.org/0000-0003-3262-6289

${ }^{3}$ Doença causada pelo coronavírus, denominado SARS-CoV-2, cujo quadro clínico abrange desde infecçōes assintomáticas até quadros mais graves. A Organização Mundial da Saúde (OMS) estima que a maioria dos pacientes com Covid-19 (cerca de 80\%) são assintomáticos ou oligossintomáticos, ou melhor, apresentam poucos sintomas. Ainda de acordo com a OMS, cerca de $20 \%$ dos casos diagnosticados necessitam de atendimento hospitalar devido a complicaçóes respiratórias e, desses casos, $5 \%$ em média precisam de suporte ventilatório. Para mais informaçôes, por favor, consulte o site: https://coronavirus.saude.gov.br/.
} 
tual, física e/ou motora, distúrbios globais do desenvolvimento, déficits de fala e comunicação, paralisia cerebral, perda auditiva, entre outras combinaçóes (Aráoz \& Costa, 2015; Chen \& Dote-Kwan, 1995; Downing, 1993). Muitas dessas crianças também apresentam condições frágeis de saúde.

Importa dizer que o termo "deficiência múltipla sensorial visual" se estrutura por uma gama de definiçóes. Isso acontece porque a natureza extremamente heterogênea dessa população impede a elaboração de uma definição sucinta. Cada uma dessas crianças apresenta necessidades únicas de aprendizagem. Portanto, o que será útil para uma criança, poderá ser desconfortável para outra (Chen \& Dote-Kwan, 1995).

Ajudar essas crianças a conquistarem habilidades de comunicação e compreenderem conceitos abstratos representa, sem dúvida, um grande desafio para os professores e profissionais. Pensando nisso, este artigo tem por objetivo apresentar cinco cartóes de símbolos tangíveis como recurso para ensinar conceitos sobre a pandemia da COVID-19 para crianças que apresentam deficiência múltipla sensorial visual.

Os benefícios dos símbolos tangíveis são pouco explorados e divulgados no cenário nacional. Nesse sentido, a utilização desses cinco cartôes de símbolos tangíveis mostra-se inédita e de grande relevância para a Educação Especial. Espera-se que este estudo seja utilizado e adaptado por outros professores para favorecer habilidades de comunicação e a compreensão de conceitos por crianças com necessidades tão complexas de aprendizagem.

\section{A IMPORTÂNCIA DO TATO PARA CRIANÇAS COM DEFICIÊNCIA MÚLTIPLA SENSORIAL VISUAL}

Quando uma pessoa não pode ver ou ouvir, ou precisa de quantidades significativas desses sentidos para conectar-se com os outros e para acessar as informaçóes do ambiente, ela desenvolve, certamente, uma forma de compensar a falta de informaçóes obtidas por meio desses sentidos. Em geral, as mãos assumem a função dos olhos e dos ouvidos para quem é cego e para quem apresenta surdocegueira (Miles, 1997).

Felizmente, o cérebro humano consegue adaptar-se para superar a perda da visão e da audição. A plasticidade do cérebro humano e suas implicaçóes para o desenvolvimento da linguagem, da comunicação e da habilidade de pessoas surdocegas para interagir com o mundo, foi o tema de uma palestra proferida pelo Doutor Harlan Lane, na Conferência Nacional da Hilton/Perkins sobre surdocegueira, realizada em Washington, Distrito de Colúmbia, Estados Unidos, em julho de 1997 (Malloy, 1997).

Quando um sentido é muito usado, o cérebro é capaz de processar as informações obtidas por meio de tal sentido com mais eficiência. Por exemplo, as pessoas que usam seus dedos de forma extensiva para ler em Braille ou para tocar instrumentos musicais de corda, mostram evidências significativas e um aumento na eficácia cortical das funçóes dos dedos (Malloy, 1997).

Além disso, as áreas do cérebro dedicadas ao processamento visual ou auditivo podem ser reativadas para realizarem informaçóes táteis, conferindo às mãos uma consistente conexão com o cérebro. Por conta disso, as mãos de uma criança surdocega ou de uma criança com deficiência múltipla sensorial visual podem ser potencialmente usadas como órgãos funcionais e 
inteligentes, permitindo que essas crianças tenham acesso às características dos objetos, estabeleçam interaçóes com outras pessoas e ampliem suas habilidades comunicativas (Miles, 1997).

Rhodes e Hewett (2010) são eloquentes ao mencionarem que o toque desempenha uma função de destaque no desenvolvimento global das crianças surdocegas e de crianças com deficiência múltipla sensorial visual, pois favorece o contato físico, efetiva experiências táteis e amplia a aprendizagem e a comunicação. $O$ fato é que as informaçóes recebidas por meio do tato são extremamente significativas para esses sujeitos. Em particular, as crianças com deficiência múltipla sensorial visual precisam ser incentivadas a envolverem-se em experiências táteis exploratórias.

Cumpre dizer que essas experiências táteis exploratórias também são chamadas de “percepção háptica”. De acordo com McLinden (2012), o termo "háptico” origina-se da palavra haptein e significa "tocar" ou "ser capaz de segurar". Para efeitos deste artigo, a percepção háptica será definida como interação tátil exploratória realizada pela criança com deficiência múltipla sensorial de forma ativa, com a intenção de identificar e reconhecer as diferentes propriedades dos objetos e do ambiente, sem o uso da visão.

Importante ressaltar que os resultados de aprendizagem para crianças com deficiência múltipla sensorial visual se centram no desenvolvimento de habilidades, em atividades que permitam que elas estabeleçam associaçóes e identifiquem diferenças, e em oportunidades de relacionarem-se com outras pessoas (Horn \& Kang, 2012).

Entretanto, por conta da intensidade de suas deficiências, muitas dessas crianças ou não exploram os objetos e nem o ambiente de forma espontânea, ou não reagem adequadamente a um estímulo sensorial. Algumas são muito responsivas aos estímulos e reagem com muita energia à estimulação; então, quando recebem um objeto para tocar, elas o batem com muita força. Outras, por sua vez, são pouco responsivas. Elas são moles, pois não têm o tônus muscular fortalecido; e, se forem incentivadas a tocarem em um objeto, provavelmente elas o soltarão ou o deixarão escorregar de suas mãos.

As crianças que reagem exageradamente à estimulação não conseguem processar adequadamente as informaçóes de um ou de todos os sentidos. Essa hipersensibilidade ao toque é descrita na literatura internacional como defensividade tátil. Essa defensividade pode ser extensiva também aos sons, configurando, assim, uma defensividade auditiva. Baranek et al. (1997) explicam que a defensividade tátil ou auditiva pode ocorrer em combinação com comportamentos estereotipados, tais como balanceios corporais para frente e para trás, uso inadequado de objetos, interesses restritos e outros.

Os autores esclarecem ainda que a defensividade tátil é tipicamente descrita como uma hipersensibilidade ou hiperresponsividade a situaçóes de toque que a maioria das pessoas não considera como ameaçadoras. Os sintomas podem variar, mas em geral manifestam-se como: ação de evitar algo indesejável; reação emocional negativa; ou ação de repelir determinada textura. Nesses casos, o essencial é observar a criança, a fim de detectar o que ela realmente gosta de tocar. A maioria dessas crianças gosta de tocar em objetos moles ou duros, não há meio termo com elas (Baranek et al., 1997). 
Certamente, um dos grandes obstáculos para iniciar uma intervenção eficaz com essas crianças consiste em identificar suas preferências e fornecer estratégias de ensino e oportunidades de aprendizagem específicas que valorizem os seus pontos fortes individuais.

\section{ENSINANDO CONCEITOS E FAVORECENDO A COMUNICAÇÁO COM SÍMBOLOS TANGÍIEIS}

A aquisição de habilidades de comunicação eficazes depende muito da qualidade do input sensorial recebido e da habilidade de interpretar esse input durante os primeiros anos do desenvolvimento (Downing, 1993). As informaçóes visuais e auditivas motivam a criança a explorar o ambiente e os objetos, a interagir com outras pessoas e a compreender que as suas ações produzem uma reação nos outros. Além disso, esses dois sentidos, especialmente a visão, favorecem a aprendizagem de conceitos de forma incidental (Downing, 1993; Chen \& DoteKwan, 1995).

Downing (1993), assim como Chen e Dote-Kwan (1995), ressalta que as crianças com deficiência múltipla sensorial visual têm acesso limitado às informaçóes, e isso diminui a motivação para explorarem, interagirem e participarem ativamente das atividades diárias. Uma vez que a aquisição da linguagem e o aprendizado de conceitos dependem fortemente de informaçóes sensoriais confiáveis, o impacto de qualquer perda visual e auditiva acarreta danos significativos no desenvolvimento global da criança. Não obstante, a combinação da perda visual ou auditiva com uma deficiência intelectual ou física mostra claramente o impacto da deficiência múltipla sensorial quanto à aquisição da linguagem funcional e da compreensão de conceitos. Como resultado, as expectativas para essas crianças podem ser reduzidas. Nesse sentido, os recursos da comunicação alternativa tátil podem favorecer a sua comunicação e atender às suas necessidades educacionais e excepcionais.

Em sua tese de Doutorado, Moreira (2020) explica que o termo "comunicação alternativa tátil" se refere a um conjunto de recursos, técnicas e estratégias que se concentram em modalidades táteis, cujo propósito consiste em oferecer informaçóes aos alunos que apresentam um funcionamento visual tão prejudicado que enfrentam dificuldades para interpretar imagens, palavras escritas em tinta e, em alguns casos, o Braille. Ainda de acordo com a referida autora, os principais recursos da comunicação alternativa tátil são os símbolos táteis, os símbolos texturizados e os símbolos tangíveis (Moreira, 2020).

Neste artigo, a ênfase recai sobre os símbolos tangíveis, os quais se referem a uma importante forma de comunicação para crianças com deficiência múltipla sensorial visual que se comunicam em um nível pré-simbólico. Os símbolos tangíveis não são apenas recursos de comunicação, mas uma sequência instrucional sistemática (Rowland \& Schweigert, 2000).

O termo "símbolo tangível” foi inicialmente introduzido na literatura internacional, em 1989, por Charity Rowland e Philip Schweigert (2009), tendo como base os trabalhos realizados por Jan Van Djik $(1966,1967)$ com crianças surdocegas, o qual, por sua vez, se baseou nas proposiçóes de Heinz Werner e Bernard Kaplan (1963).

Contudo, por que usar símbolos tangíveis com crianças com deficiência múltipla sensorial visual? Porque eles exigem menos memória e habilidades representacionais que os símbolos abstratos (Rowland \& Schweigert, 2000). Podem ser bidimensionais, como imagens, 
ou tridimensionais, como objetos reais, parte de objetos ou objetos pequenos que podem ser fixados em cartóes contendo legendas escritas em tinta e em Braille. São facilmente manuseados e relacionam-se claramente com seus referentes (Rowland \& Schweigert, 2009; Trief, 2007).

Além disso, os símbolos tangíveis são usados para representar locais, alimentos, pessoas, atividades, eventos e conceitos (Trief et al., 2019). Podem ser usados para antecipar atividades em que os objetos funcionam como pistas perceptivas dentro de determinado contexto, como recursos de comunicação, atendendo aos propósitos da comunicação receptiva e expressiva, e podem ser usados para incentivar a criança a fazer escolhas (Rowland \& Schweigert, 2009).

Existem diversos termos utilizados como sinônimos de símbolos tangíveis, como, por exemplo: dicas de objetos (Lancioni et al., 2002), objetos de referência (Park, 1997), dicas de antecipação (Joffee \& Rikhye, 1991), símbolos táteis (Lund \& Troha, 2008) e pistas tangíveis (Rowland \& Schweigert, 2009).

A seguir, encontram-se os cinco cartóes de símbolos tangíveis que foram elaborados para representar os conceitos sobre a pandemia da COVID-19.

\section{Figura 1}

Cartão de símbolo tangivel-Coronavirus

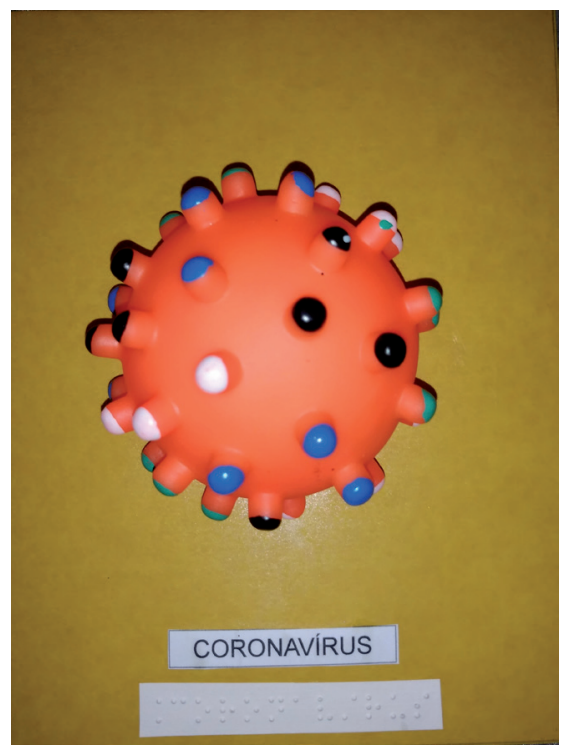

A Figura 1 mostra um cartão amarelo, feito com papel cartão, medindo 15 x $20 \mathrm{~cm}$, plastificado com papel contact transparente. É importante ressaltar que os demais cartóes foram elaborados com essas mesmas características. No meio desse cartão, há uma bola de borracha, na cor laranja, texturizada com gomos nas pontas com as cores azul, branco, preto e verde. A bola está firmada com velcro, assim como os outros objetos apresentados nas figuras a seguir. $\mathrm{Na}$ parte inferior, há uma legenda escrita em tinta e outra legenda escrita em Braille a palavra “CORONAVÍRUS” em letras maiúsculas. 


\section{Figura 2}

Cartão de simbolo tangivel-Me deixa doente

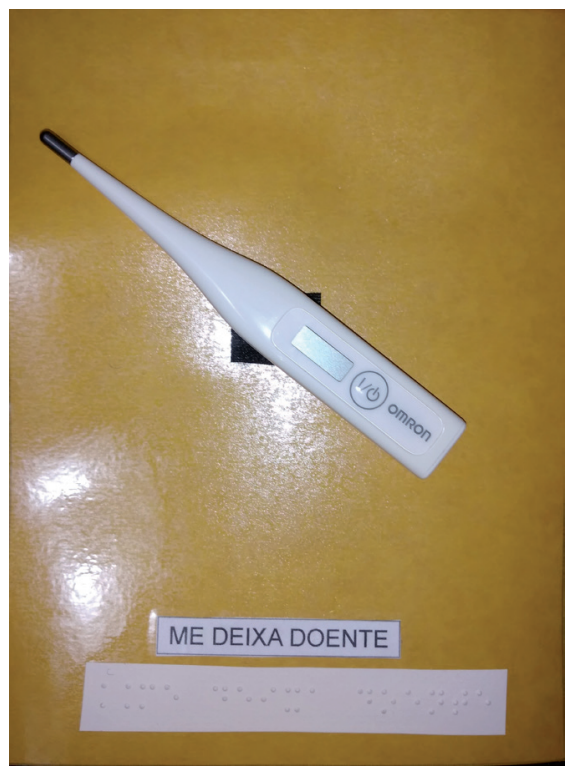

A Figura 2 apresenta um cartão amarelo, feito com papel cartão, medindo 15 x 20 $\mathrm{cm}$, plastificado com papel contact transparente. No meio desse cartão, há um termômetro digital branco fixado com velcro. Na parte inferior, há uma legenda escrita em tinta e outra legenda escrita em Braille a frase "ME DEIXA DOENTE” em letras maiúsculas.

\section{Figura 3}

Cartão de simbolo tangivel-Preciso lavar

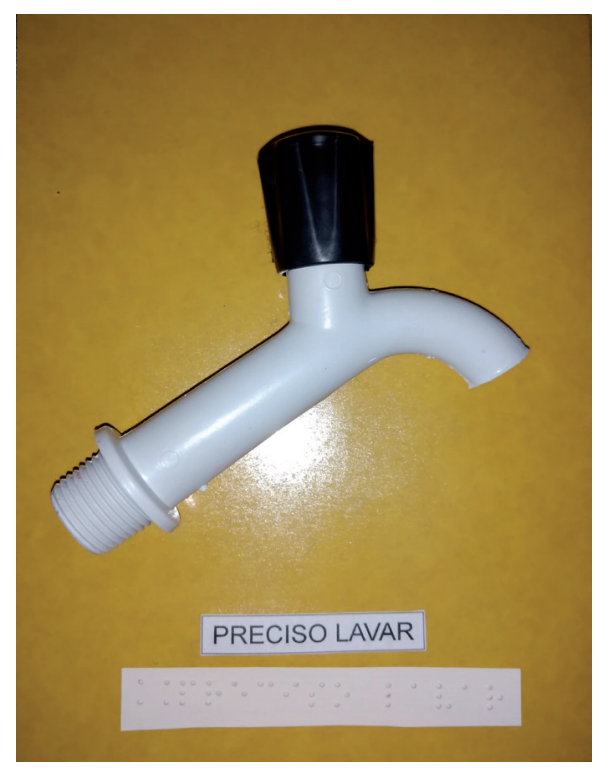


Já a Figura 3 revela um cartão amarelo, feito com papel cartão, medindo $15 \times 20 \mathrm{~cm}$, plastificado com contact transparente. No meio desse cartão, há uma torneira de plástico branca com manopla preta segurada pelo velcro. Na parte inferior, há uma legenda escrita em tinta e outra legenda escrita em Braille a frase "PRECISO LAVAR" em letras maiúsculas.

\section{Figura 4}

Cartão de Simbolo Tangivel-As mãos

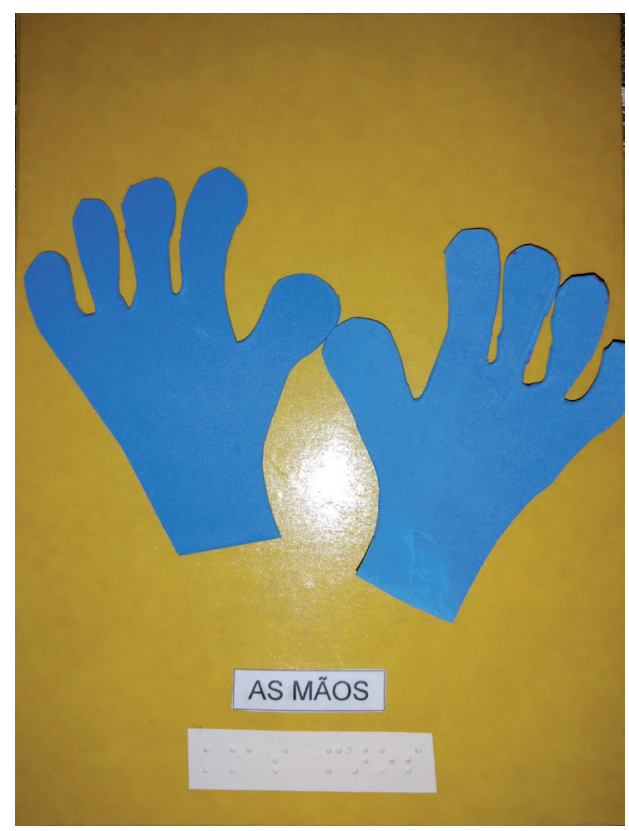

A Figura 4 mostra um cartão amarelo, feito com papel cartão, medindo $15 \times 20 \mathrm{~cm}$, plastificado com contact transparente. No meio desse cartão, há duas mãos (direita e esquerda), feitas com E.V.A. azul. Cada mão está fixada com velcro. Na parte inferior, há uma legenda escrita em tinta e outra legenda escrita em Braille a frase "AS MÃOS" em letras maiúsculas. 


\section{Figura 5}

Cartão de Símbolo Tangível-E usar máscara

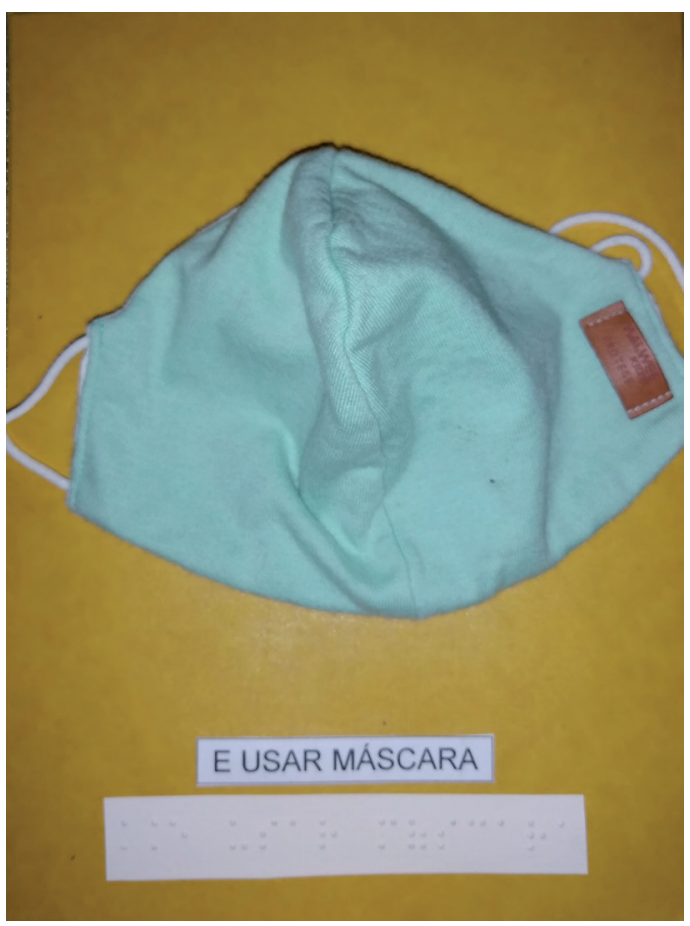

A Figura 5 apresenta um cartão amarelo, feito com papel cartão, medindo 15 x 20 $\mathrm{cm}$, plastificado com contact transparente. No meio desse cartão, há uma máscara infantil de tecido algodão na cor verde-clara, pregada com velcro. Na parte inferior, há uma legenda escrita em tinta e outra legenda escrita em Braille a frase "E USAR MÁSCARA” em letras maiúsculas.

Como mencionado anteriormente, todos os objetos foram pregados aos cartóes com velcro, pois a utilização desses cartóes não deve ocorrer de forma aleatória, mas por meio de uma sequência instrucional.

Inicialmente, a criança precisa manusear os objetos soltos para conhecê-los. Os objetos devem ser colocados dentro de uma área delimitada, como uma caixa, para que a criança brinque com eles e os explore da forma como desejar. A seguir, a Figura 6 mostra como esses objetos podem ser apresentados à criança. 


\section{Figura 6}

Caixa para exploração dos objetos soltos

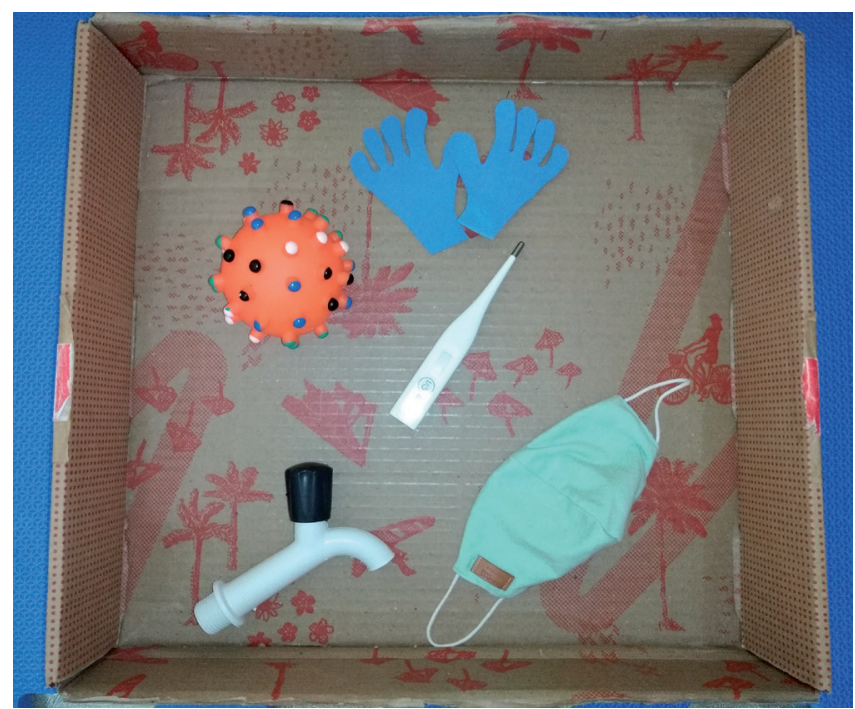

A Figura 6 mostra uma caixa de papelão em cima de um tatame azul com uma bola de borracha, na cor laranja, texturizada com gomos coloridos nas pontas de azul, branco, preto e verde, uma torneira de plástico branca com manopla preta, uma máscara infantil de tecido algodão, na cor verde-claro, um termômetro digital branco e duas mãos, na cor azul, feitas de E.V.A.

Em seguida, esses objetos devem ser transformados em símbolos tangíveis, ao serem pregados em cartóes. É muito importante conversar com a criança e explicar o significado de cada objeto dentro de um contexto específico, no caso em questão, a pandemia da COVID-19. $\mathrm{Na}$ Figura 7 que segue, os cinco cartóes de símbolos tangíveis encontram-se organizados para dar sentido a uma frase.

\section{Figura 7}

Cartóes de simbolos tangiveis formando uma frase

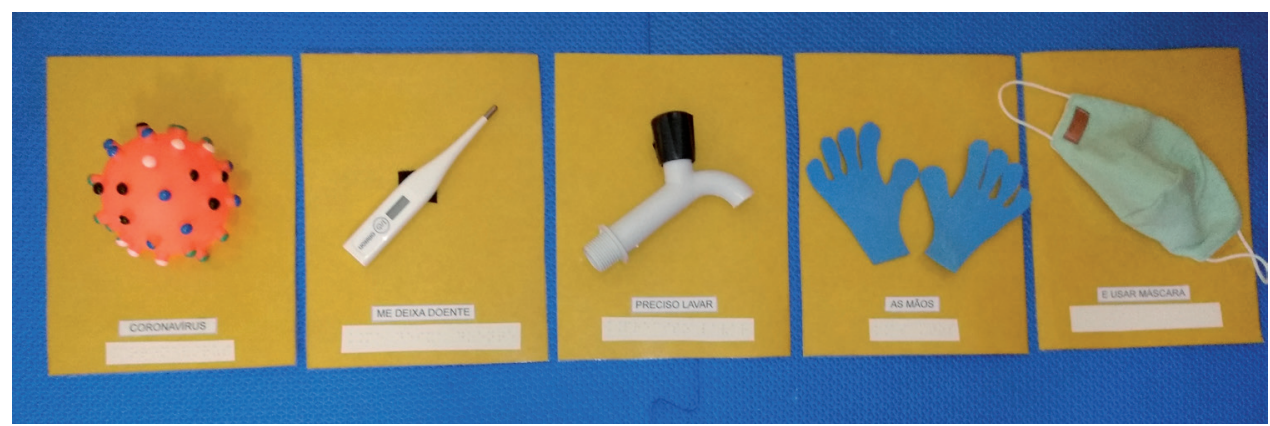

A Figura 7 mostra os cinco cartóes de símbolos tangíveis apresentados e descritos anteriormente, organizados em cima de um tatame azul, para formar a seguinte fra- 
se: "CORONAVÍRUS ME DEIXA DOENTE, PRECISO LAVAR AS MÁOS E USAR MÁSCARA". Da esquerda para direita, tem-se o cartão referente ao "coronavírus"; em seguida, o cartão "me deixa doente"; na sequência o cartão "preciso lavar"; a seguir, tem-se o cartão "as mãos"; e, por fim, o cartão "e usar máscara”.

Mesmo que a criança ainda não use a linguagem oral ou mesmo que rejeite o uso da máscara, é importante que ela tenha contato com esses objetos a fim de lhes atribuir significado e conhecer o uso funcional de cada um. No entanto, como orientar a criança para conhecer esses cartóes? Antes de responder a essa pergunta, convém sublinhar o potencial das mãos e de suas implicações na aquisição de informações e habilidades por crianças com deficiência múltipla sensorial visual.

A esse respeito, Miles (1997) é enfática ao mencionar que a aquisição de habilidades manuais durante a infância depende do crescente interesse em usar as mãos como ferramentas para explorar e agir sobre objetos e pessoas, para se mover e formar um senso de identidade com o ambiente. As mãos são uma importante forma de expressão e desempenham um importante papel no desenvolvimento da linguagem. Contudo, para crianças que não enxergam e apresentam outras deficiências associadas à deficiência visual, a situação é diferente. Sem a visão, a tarefa de usar as mãos como ferramentas para explorar e obter informaçóes sobre o ambiente requer um esforço extensivo (Miles, 1997).

Como a interação tátil exploratória não acontece de modo espontâneo, essas crianças precisam ser encorajadas a usarem as mãos para formarem conceitos sobre o mundo. $\mathrm{O}$ primeiro passo consiste em conhecer a criança e identificar suas preferências, o que a deixa irritada e quando ela está com mais disposição. É importante também respeitar o seu tempo de entendimento e o tempo que leva para responder a um determinado estímulo. Os parceiros de comunicação devem ter interesse e disposição para interagirem com a criança no tempo dela.

Assim sendo, uma forma viável de orientar a criança a conhecer os cartóes de símbolos tangíveis propostos neste estudo baseia-se na estratégia "mão sobre mão". Ela consiste em o adulto colocar sua mão embaixo da mão da criança e conduzi-la para pesquisar determinado objeto (Miles, 1997). Essa estratégia não é controladora e nem invasiva, pois deixa a criança à vontade para pesquisar ou não.

Desse modo, a orientação para que a criança toque e explore os cartóes de símbolos tangíveis deve ocorrer da seguinte forma: o adulto precisa conversar com a criança e explicar o significado de cada objeto e de cada cartão; depois, colocar a mão embaixo da mão da criança para direcioná-la a explorar cada um dos cartôes, dando tempo de entendimento e tempo de resposta para ela se expressar.

Frequentemente, essas crianças lutam para compreender o significado dos símbolos, pré-requisito necessário para a aquisição da linguagem (Bruce, 2005). Werner e Kaplan (1988) ressaltam a importância do distanciamento entre o símbolo e a sua representação. Bruce (2005) explica que, sem o distanciamento, a pessoa fica presa ao momento presente sem poder se comunicar a respeito de pessoas e de objetos, a menos que estes estejam no cenário atual.

O distanciamento é um processo gradual que inclui a separação física e psicológica do eu, dos outros e dos objetos. A capacidade de compreender que algo serve para representar 
outra é condição essencial para o desenvolvimento da comunicação e da compreensão de conceitos (Bruce, 2005).

Werner e Kaplan (1988) definiram quatro componentes elementares da expressão simbólica: o emissor da mensagem; o destinatário; o objeto a ser representado; e a representação. À medida que as crianças avançam no uso e no entendimento dos símbolos tangíveis dentro de determinado contexto, elas estabelecem uma distância crescente entre si e os seus parceiros de comunicação, entre si e os objetos a serem representados e entre as diferentes etapas de representação (Bruce, 2005).

Evidências apontam que o distanciamento pode ocorrer também quando os objetos são usados como símbolos de antecipação de atividades pelas crianças. Quando o pensamento simbólico é alcançado, as crianças adquirem a habilidade de comunicarem-se a respeito de determinado referente sem que ele esteja presente no contexto atual (Bruce, 2005).

O estabelecimento da distância pelas crianças com os outros depende do entendimento que elas têm de si como indivíduos separados. Essa compreensão ocorre, a princípio, em relação a elas mesmas e seus principais cuidadores (pais, familiares ou responsáveis) e, em seguida, estende-se aos demais parceiros de comunicação (Bruce, 2005).

O distanciamento entre a criança e os objetos baseia-se na qualidade de suas experiências motoras com eles. Depreende-se dessa situação a importância de encorajar a criança a tocar, a fim de incentivar a interação tátil exploratória (McLinden, 2012). Considerando que algumas crianças apresentam defensividade tátil em relação a determinadas texturas, convém apoiar essas exploraçóes por meio de experiências compartilhadas entre a criança e o adulto, os quais devem estabelecer uma atenção conjunta em torno de um objeto (Bruce, 2005).

Tendo em vista esses aspectos, a utilização dos objetos, como símbolos de comunicação, como recursos de comunicação, como opçóes de escolhas e como possibilidades para a compreensão de conceitos, deve ser introduzida a partir das características de cada criança, valorizando suas preferências e seus pontos fortes. É fundamental valorizar as experiências naturais que se desenrolam durante a rotina diária da criança, seja em casa ou na escola. A sedimentação de conceitos relaciona-se diretamente às experiências individuais e diárias de cada um.

\section{Conclusão}

Os símbolos tangíveis são um dos recursos da comunicação alternativa tátil. Podem ser utilizados para favorecer a comunicação, para incentivar as crianças a fazerem escolhas e contribuem para a formação de conceitos. Não são padronizados, mas devem ser utilizados obedecendo uma sequência instrucional de forma consistente.

A elaboração dos símbolos tangíveis emprega materiais de baixo custo. São objetos reais ou parte de objetos que se relacionam claramente com seus referentes. Esses recursos configuram-se como essenciais para a compreensão de conceitos por parte de crianças com deficiência múltipla sensorial visual. Eles devem ser utilizados pela criança de forma contínua, de modo que haja uma integração entre o ambiente doméstico e a escola. Ressalta-se a importância dos parceiros de comunicação para compartilharem experiências e estabelecerem atenção conjunta a essas crianças, bem como a importância do contexto social para a compreensão de conceitos. 
Para McLinden (2012), o desenvolvimento da função háptica, ou melhor, da interação tátil exploratória nas crianças videntes, surge na primeira infância e continua a ocorrer durante toda essa fase. Nas crianças com deficiência múltipla sensorial visual, essa habilidade requer incentivo e apoio, por isso quanto mais conhecimento tátil a criança tiver, melhor será sua memória tátil e seu entendimento sobre o ambiente.

Nesse sentido, é essencial o suporte do adulto para garantir a evolução e o engajamento da criança para explorar ativamente e conhecer os atributos dos objetos. Em relação aos cartóes apresentados neste artigo, esse suporte fez-se necessário para efetivar o entendimento concreto a respeito de alguns aspectos sobre a pandemia da COVID-19. Sua utilização deve ocorrer de forma consistente, seguindo a sequência instrucional detalhada anteriormente e de forma repetida.

Existem diversas possibilidades para implementar o uso de símbolos tangíveis. O que foi apresentado neste estudo não é fixo e nem padronizado. Os professores devem realizar suas próprias adaptações, pois o mais importante é que tenha significado para a criança e que o uso desses recursos siga a sequência instrucional. Além disso, este texto não tem a intenção de esgotar esse assunto, mas motivar a realização de outras propostas. Espera-se que outros professores e pesquisadores possam utilizá-los e adaptá-los para atender às necessidades de seus alunos em outros contextos.

\section{REFERÊNCIAS}

Aráoz, S. M. M., \& Costa, M. P. R. (2015). Deficiência múltipla as técnicas MAPA e CAMINHO no apoio à inclusão. Paco Editorial.

Baranek, G. T.; Foster, L. G., \& Berkson, G. (1997). Tactile defensiveness and stereotyped behaviors. The American Journal of Occupational Therapy, 51(2), 91-95. https://doi.org/10.5014/ajot.51.2.91

Bruce, S. M. (2005). The application of Werner and Kaplan's concept of "distancing” to children who are deaf-blind. Journal of Visual Impairment and Blindness, 99(8), 1-27. https://doi. org/10.1177/0145482X0509900803

Chen, D., \& Dote-Kwan, J. (1995). Starting points: instructional practices for young children whose multiple disabilities include visual impairment. Blind Children's Center.

Downing, J. E. (1993). Communication intervention for individuals with dual sensory and intellectual impairments. Clinics in Communication Disorders, 3(2), 31-42.

Horn, E. M., \& Kang, J. (2012). Supporting young children with multiple disabilities: what do we know and what do we still need to learn?. Topics in Early Childhood Special Education, 31(4), 241248. https://doi.org/10.1177/0271121411426487

Joffee, E., \& Rikhye, C. H. (1991). Orientation and mobility for students with severe visual and multiple impairments: A new perspective. Journal of Visual Impairment and Blindness, 85(5), 211216. https://doi.org/10.1177/0145482X9108500506

Lancioni, G. E., O'reilly, M. F., \& Oliva, D. (2002). Engagement in cooperative and individual tasks: assessing the performance and preference of persons with multiple disabilities. Journal of Visual Impairment and Blindness, 96(1), 50-53. https://doi.org/10.1177/0145482X0209600106

Lund, S. K., \& Troha, J. M. (2008). Teaching young people who are blind and have autism to make requests using a variation on the picture exchange communication system with tactile symbols: A preliminary investigation. Journal of Autism and Developmental Disorders, 38(4), 719-730. https:// doi.org/10.1007/s10803-007-0439-4 
Malloy, P. (1997). Communication and culture: how they relate to service development and advocacy for people who are deaf-blind. A Report on a Presentation by Dr. Harlan Lane at the Hilton/ PerkinsNational Conference On Deafblindness. Deaf-Blind Perspectives, 5(1), 7-9.

McLinden, M. (2012). Mediating haptic exploratory strategies in children who have visual impairment and intelectual disabilities. Journal of Intellectual Disability Research, 56(2), 129-139. https://doi. org/10.1111/j.1365-2788.2011.01430.x

Miles, B. (1997). Talking the language of the hands to the hands: the importance of hands for the person who is deafblind. National Information Clearinghouse on Children who are Deaf-Blind, Monmouth, OR, 2-14.

Moreira, F. D. S. (2020). PACT - Programa de comunicação alternativa tátil para crianças com deficiência múltipla sensorial [Tese de Doutorado, Faculdade de Educaçáo, Universidade do Estado do Rio de Janeiro]. Repositório da Universidade do Estado do Rio de Janeiro. http://acervo.ibc.gov.br/

Park, K. (1997). How do objects become objects of reference: A review of the literature on objects of reference and a proposed model for the use of objects in communication. British Journal of Special Education, 24(3), 108-114. https://doi.org/10.1111/1467-8527.00025

Rhodes, J., \& Hewett, D. (2010). The human touch: physical contact and making a social world available for the most profoundly disabled. PMLD-Link, 22(66), 11-13. http://www.pmldlink.org. uk/wp-content/uploads/2015/09/PMLD-Link-Issue-66.pdf

Rowland, C., \& Schweigert, P. (2009). Tangible symbols: symbolic communication for individuals with multisensory impairments. Augmentative and Alternative Communication, 5(4), 226-234. DOI: https://doi.org/10.1080/07434618912331275276

Rowland, C., \& Schweigert, P. (2000). Tangible symbols systems: making the right to communicate a reality for individual with severe disabilities. Design to Learn.

Trief, E. (2007). The use of tangible cues for children with multiple disabilities and visual impairment. Journal of Visual Impairment and Blindness, 101(10), 613-619. https://doi. org/10.1177/0145482X0710101006

Trief, E., Bruce, S. M., Cascella, P. W., \& IVY, S. (2019). The development of a universal tangible symbol system. Journal of Visual Impairment and Blindness, 103(7), 425-430. https://doi. org/10.1177/0145482X0910300706

Van Dijk, J. (1966). The first steps of the deaf-blind child toward language. International Journal for the Education of the Blind, 15(4), 112-114.

Van Dijk, J. (1967). The non-verbal deaf-blind child and his world: His outgrowth towards the world of symbols. Jaarverslag, lnstitut voor Doven.

Werner, H., \& Kaplan, B. (1963). Symbol formation. John Wiley.

Werner, H., \& Kaplan, B. (1988). On developmental changes in the symbolic process. In: M. B. Franklin \& S. S. Barton (Ed.), Child language: a reader ( $1^{\text {st }}$ ed., pp. 7-9). Oxford University Press.

Recebido em: 08/10/2020

Reformulado em: 14/01/2021

Aprovado em: 27/02/2021 
MOREIRA, F.D.S. 